\title{
A VIDA APÓS O TRANSPLANTE DE MEDULA ÓSSEA: IMPLICAÇÕES PARA O COTIDIANO*
}

\author{
Angélica Mônica Andrade¹, Edna Aparecida Barbosa de Castro², Kelli Borges dos Santos ${ }^{3}$ \\ Teresa Cristina Soares ${ }^{4}$
}

\begin{abstract}
RESUMO: Estudo qualitativo buscou compreender as vivências de adultos submetidos ao transplante de medula óssea autólogo e identificar as implicações no cotidiano dos sujeitos que o vivenciam. Foram realizadas entrevistas orientadas por roteiro semiestruturado, com sete adultos transplantados residentes em um município do interior de Minas Gerais e que tiveram alta entre de outubro de 2004 e setembro de 2010. Evidenciaram-se questões relativas às implicações no cotidiano das pessoas com mudanças na vida após o transplante de medula óssea. Após a análise de conteúdo temática surgiram três categorias empíricas: Afastamento do trabalho; Estado de vigília: preocupação constante com recidivas após a alta e Reestruturação da vida após o transplante de medula óssea - ressignificações do existir. Conclui-se que é necessária a incorporação de condutas profissionais permeadas de adaptação, utilizando-se diferentes estratégias, como criatividade, emoção e, sobretudo, saber científico.
\end{abstract}

PALAVRAS-CHAVE: Transplante de medula óssea; Adaptação; Atividades cotidianas; Emoções.

\section{LIFE AFTER BONE MARROW TRANSPLANT: IMPLICATIONS FOR DAILY ROUTINES}

ABSTRACT: This qualitative study sought to understand the experiences of adults who had submitted to autologous bone marrow transplant and to identify the implications for daily routines in the individuals who had gone through it. Interviews were undertaken, guided by a semi-structured script, with seven adult inpatients who had undergone the transplant, in a country town in the state of Minas Gerais, and who had been discharged between October 2004 and September 2010. Evidence was found for questions relevant to implications for daily routines of the people, with changes in life after the bone marrow transplant. After thematic content analysis, three empirical categories emerged: Withdrawal from work; Sleeplessness: Constant worry about relapses after discharge and Restructuring of one's life after bone marrow transplant-redefining existing. It is concluded that it is necessary to incorporate thoroughly adaptive professional conduct, using different strategies such as creativity, emotion and, above all, scientific knowledge. KEYWORDS: Bone marrow transplant; Adaptation; Routine activities; Emotions.

\section{LA VIDA DESPUÉS DEL TRANSPLANTE DE MÉDULA ÓSEA: IMPLICACIONES PARA EL COTIDIANO}

RESUMEN: Estudio cualitativo cuyo objetivo fue comprender las vivencias de adultos sometidos al transplante de médula ósea autólogo e identificar las implicaciones en el cotidiano de los sujetos que pasaron por ese proceso. Fueron realizadas entrevistas orientadas por guión semi estructurado, con siete adultos trasplantados que viven en un municipio del interior de Minas Gerais y que tuvieron alta entre octubre de 2004 y septiembre de 2010. Se evidenciaron cuestiones referentes a las implicaciones en el cotidiano de las personas con cambios en la vida después del transplante de médula ósea. Después del análisis de contenido temático surgieron tres categorías empíricas: Alejamiento del trabajo; Estado de vigilia: preocupación constante con recidivas después de alta y Restructuración de la vida después del transplante de médula ósea - resignificaciones del existir. Se concluye que es necesaria la adopción de conductas profesionales permeadas de adaptación, utilizándose diferentes estrategias, como creatividad, emoción y, sobretodo, saber científico. PALABRAS CLAVE: Transplante de médula ósea; Adaptación; Actividades cotidianas; Emociones.

\footnotetext{
*Artigo originado de monografia apresentada ao Curso de Especialização em Políticas e Pesquisa em Saúde Coletiva do Núcleo de Assessoria, Treinamento e Estudos em Saúde da Universidade Federal de Juiz de Fora - UFJF.

${ }^{1}$ Enfermeira. Especialista em Enfermagem Saúde do Adulto e em Políticas e Pesquisa em Saúde Coletiva. Mestranda em Enfermagem pela Universidade Federal de Minas Gerais. Bolsista CNPq.

${ }^{2}$ Enfermeira. Doutora em Saúde Coletiva. Professora do Departamento de Enfermagem Aplicada da Faculdade de Enfermagem da UFJF. ${ }^{3}$ Enfermeira. Mestre em Saúde Coletiva. Professora do Departamento de Enfermagem Básica da Faculdade de Enfermagem da UFJF. Enfermeira do Serviço de Transplante de Medula Óssea do Hospital Universitário da UFJF.

${ }^{4}$ Enfermeira e psicóloga. Doutora em Saúde Pública. Professora do Departamento de Enfermagem Aplicada da Faculdade de Enfermagem da UFJF.
}

Autor correspondente:

Angélica Mônica Andrade

Universidade Federal de Minas Gerais

Av. Dr. Cristiano Guimarães, 174 - 31720-300 - Belo Horizonte-MG-Brasil

E-mail: angelicamonica.andrade@gmail.com
Recebido: 24/11/2011

Aprovado: 17/05/2012

Cogitare Enferm. 2012 Abr/Jun; 17(2):290-6 


\section{INTRODUÇÃO}

Pessoas que vivenciam a conclusão diagnóstica de determinados tipos de doenças hematológicas, oncológicas, hereditárias e imunológicas, por vezes recebem, como parte da definição da terapêutica médica, a indicação para realização do transplante de células-tronco hematopoéticas, também conhecido por transplante de medula óssea $(\mathrm{TMO})^{(1)}$. Este tratamento consiste na infusão de células-tronco hematopoéticas sadias no paciente que apresenta alguma destas patologias, com a finalidade de restabelecer-lhe a função da medula óssea doente. Previamente à infusão das células sadias, a medula doente é destruída por altas doses de quimioterapia e/ou radioterapia ${ }^{(1)}$.

Existem três tipos de TMO, o autogênico ou autólogo, o singênico e o alogênico ${ }^{(2)}$. No transplante autogênico, as células-tronco são obtidas do próprio paciente, armazenadas, congeladas e reinfundidas posteriormente. No transplante singênico, as células são obtidas de um irmão gêmeo idêntico; e no alogênico, as células são obtidas de um doador compatível ${ }^{(2-3)}$.

A vida das pessoas submetidas ao TMO sofre modificações decorrentes, em parte, do longo processo vivenciado desde o diagnóstico até a alta hospitalar, o qual atua como um desencadeador de vivências de ansiedade que interferem em seu cotidiano de vida e de seus familiares. Acrescenta-se que, devido à complexidade do tratamento, elas apresentam longos períodos de hospitalização, caracterizando uma condição de isolamento social que gera mudanças existenciais, sinalizadoras da necessidade de adaptação a um novo estilo de vida.

Após a alta do hospital, é necessário que esses pacientes recebam acompanhamento ambulatorial por um longo período, durante o qual existe a possibilidade de complicações decorrentes do tratamento e, ainda, da recidiva da doença ${ }^{(4)}$. As complicações e impactos relativos ao procedimento podem variar segundo o tipo de transplante, a doença de base, os condicionamentos propostos e os medicamentos usados ${ }^{(5)}$. Há complicações relacionadas à toxicidade das drogas utilizadas, à rejeição do enxerto, complicações infecciosas, pneumonite intersticial, doença veno-oclusiva hepática, os quais aumentam a morbidade e as mortes pelo tratamento ${ }^{(2,6)}$.

Desse modo, em todas as fases do tratamento há sofrimento físico e psíquico, com alterações significativas do cotidiano, surgindo, assim, uma série de demandas e necessidades ${ }^{(7)}$. Dentre elas, destacam-se as necessidades de atenção relacionadas à incerteza do futuro, ao afastamento do trabalho e à ausência da família ${ }^{(5)}$.
Salienta-se que, após a alta, o paciente deve, gradativamente, substituir o ambiente hospitalar pelo domiciliar, e dar início a uma construção progressiva de autonomia e busca pelo autocuidado ${ }^{(8)}$. Neste cenário de adaptação, torna-se essencial que o enfermeiro, em sua dimensão assistencial, insira-se de maneira efetiva com seu processo de cuidar sistematizado, tendo em vista a sua presença contínua, junto aos pacientes e seus familiares, durante a trajetória terapêutica e o vínculo que se estabelece ${ }^{(9)}$.

Em face do exposto, considera-se relevante investigar o período após o TMO e suas implicações na vida dos pacientes, a fim de avançar e aprofundar o conhecimento sobre as suas necessidades de cuidados de enfermagem. Em especial, estudos compreensivos que evidenciem as capacidades e os enfrentamentos; as limitações e as dificuldades, seja do paciente, seja da família ou de ambos, a fim de contribuir para a definição das intervenções que qualifiquem a atenção à saúde das pessoas que vivenciam a experiência do transplante, o que, afinal, é direito de todo cidadão.

Dessa forma, esta investigação objetivou compreender as vivências de adultos submetidos ao transplante de medula óssea autólogo e identificar as implicações no cotidiano dos sujeitos que o vivenciam.

\section{MÉTODO}

Realizou-se um estudo com abordagem qualitativa, tendo em vista o entendimento de que as questões norteadoras encontram-se no interior de relações humanas, envolvendo o contexto de vida e a subjetividade das respostas das pessoas que se submetem ao $\mathrm{TMO}^{(10)}$.

Como critérios de elegibilidade incluíram-se, nesta investigação, adultos residentes no município sede da pesquisa, submetidos a TMO autólogo, que se encontravam na faixa etária ente 18 e 59 anos, independente de gênero, etnia, estado civil, escolaridade, credo religioso, posição política e condição social. Participaram aqueles que obtiveram alta no período de outubro de 2004 a setembro de 2010 do serviço de hematologia de um hospital público de ensino do interior de Minas Gerais, cenário da pesquisa, que se encontravam conscientes e aceitaram espontaneamente a participar. Excluíram-se, pois, os que se submeteram a outros tipos de TMO que não o autólogo, que se encontravam fora da faixa etária estipulada, que foram ao óbito e os que residiam fora do município sede da pesquisa.

Esclarece-se que, no contexto da rede de atenção à saúde do município, o cenário da pesquisa refere-se a um serviço credenciado como de alta complexidade e de 
referência nacional, que recebe pacientes de diferentes municípios de Minas Gerais, e ainda, de outros estados brasileiros. Nesse cenário, identificou-se nos registros de admissão e alta, o universo de 131 pacientes submetidos ao TMO autólogo até a data de início da coleta de dados. Destes, 7 eram menores de 18 anos, 20 maiores de 59 anos, 38 foram ao óbito e 54 residiam fora do município sede da pesquisa. Selecionou-se, portanto, 12 pacientes como potenciais sujeitos da pesquisa.

Após o levantamento prévio nos prontuários, procedeu-se ao contato por telefone para a localização e confirmação dos potenciais participantes. Nesta fase, dois deles não foram localizados pelos números de telefone registrados nos prontuários. Dos que foram identificados, três recusaram-se a participar da pesquisa. Passou-se, em seguida à etapa de visitas domiciliares junto aos 7 sujeitos, sendo cinco mulheres e dois homens.

Optou-se pelas visitas domiciliares como estratégia de coleta de dados por permitirem entrevista no contexto natural de vivência do sujeito e a observações do cotidiano dos mesmos após a alta do transplante, bem como a trama de relações que a partir daí se estabelece. Adotou-se como técnica a entrevista guiada por roteiro semiestruturado, gravada em meio digital e o registro das observações em um diário de campo. Apenas um dentre os sujeitos preferiu que a entrevista ocorresse no ambulatório, na data de retorno para a consulta de controle. A transcrição das entrevistas foi feita na íntegra, identificando aspectos relevantes à análise e orientadores das buscas nas visitas seguintes.

Para a realização desta investigação foram respeitados os preceitos éticos em pesquisa com seres humanos, em que foram assegurados o sigilo, a confidencialidade das informações e o anonimato, conforme Resolução n. 196/96 do Conselho Nacional de Saúde ${ }^{(11)}$. A fase de coleta de dados foi realizada após apreciação e aprovação do Comitê de Ética em Pesquisa referente à Instituição do estudo, com protocolo de aprovação de número 202/2010 - CAAE 0073.0.420.180-10 e após a assinatura do Termo de Consentimento Livre e Esclarecido pelos sujeitos do estudo. Para resguardar a identidade dos entrevistados, utilizaram-se nomes de flores.

Para a análise do material empírico adotou-se a análise de conteúdo temática a partir da leitura exaustiva e interpretação de notas de observação e das entrevistas transcritas, das quais se buscaram destacar as mudanças ocorridas nas vidas dos indivíduos por meio das recorrências, tendências e dos pontos de convergência $^{(12)}$. Após a extração dos elementos textuais foram construídas três categorias empíricas: Afastamento do trabalho; Estado de vigília: preocupação constante com recidivas após a alta, e $A$ vida após o transplante de medula óssea - ressignificações do existir.

\section{RESULTADOS}

\section{Afastamento do trabalho}

A mudança no exercício da ocupação ou profissão após o TMO, ou seja, no processo de retomada do cotidiano de vida foi o aspecto que mais imediatamente se evidenciou nas falas dos sujeitos pesquisados. Estes exerciam diferentes profissões e ocupações anteriormente ao transplante, que eram as seguintes: contadora, médica, secretária, vendedora, motorista, estudante e dona de casa.

Os sujeitos explicitaram situações e fizeram comparações entre o estilo de vida antes e após o TMO, enfatizando as restrições relacionadas ao exercício profissional. Margarida, de 42 anos, divorciada, submeteuse ao TMO autólogo em decorrência de uma leucemia. Antes do procedimento, exercia medicina; ao falar de sua vida após o TMO, iniciou assim:

Bom, eu tive que reestruturar minha vida. Eu fazia muito plantão, e trabalhava no hospital [...] então, eu tive que me readaptar. Não, criar uma outra vida! Então, dentro de casa eu cuido da casa. Não, eu tenho empregada, mas eu faço, eu virei dona de casa, faço os pagamentos, faço as compras. Mas, eu não voltei a trabalhar. [...] eu tinha o emprego que eu queria, fazia o plantão que eu queria, no lugar que eu queria. Então, isso tudo acabou. Essa vida de trabalhar, onde eu gostava e muito, acabou e eu tive que me adaptar para poder mudar o foco. (E2 Margarida)

Atualmente ela passa os dias em casa, sem a esperança de retornar ao exercício profissional. Os depoimentos também remetem a um sentimento de frustração e invalidez por parte de alguns sujeitos em relação ao afastamento de sua atividade profissional, demonstrando uma grande vontade de retornar, mas sempre esbarrando em alguma restrição, seja física, médica ou psicológica. É o que se percebe nas seguintes falas:

Ele me tirou do trabalho, en era apaixonado pelo meu trabalho, sempre gostei. Eu trabalho com trator. Eu não consigo trabalhar mais, eu não tenho força para trabalhar, é um serviço muito bruto. Eu não tenho nem coragem de trabalhar mais o dia que eu tiver alta médica, eu não vou conseguir trabalhar mais não. 
Não tenho mais cabeça para isso não. Eu fiquei fraco, minha mente está muito fraca, não consigo mais não. (E4 Lírio)

No momento que eu fiz o tratamento, eu não ligava muito. Mas aí, só depois que eu tive a recaída agora, que eles me aposentaram. Ai, eu fiquei desesperada, sabe, me sentindo inválida, é horrivel. Eu queria trabalhar. (E6 Violeta)

Estado de vigília: preocupação constante com recidivas após a alta

Durante as entrevistas, os sujeitos demonstram a preocupação constante com o pós-transplante, mais especificamente, com a possibilidade de recidiva da doença. Notou-se, nos sujeitos nesse período, o surgimento de um estado de vigília. Rosa e Margarida o trouxeram à tona de modo explícito, como se observa nos trechos de suas falas a seguir:

[...] e depois do transplante, eu não sei, depois do transplante eu ainda estou fazendo o tratamento. Em julho, quando eu fiz a última tomografia, deu ainda lesão no pulmão, então a gente fica na ansiedade, né? Será que tem? Será que não tem? Vamos ver. (E1 Rosa)

Era toda vez que eu ia fazer exame, receber o resultado, desespero, para saber se aquele negócio [...]. Essa era a minha necessidade, o resto era o resto, mas receber, ver o resultado do exame para ver se estava indo certinho, era a única coisa que, para mim, importava. Era ver o resultado daquele exame. (E2 Margarida)

As falas evidenciam a preocupação dos sujeitos em realizar os exames para a confirmação do seu estado de saúde como, por exemplo, exames de sangue, que são necessários após o transplante, e que todos os pacientes realizam. Portanto, o sentimento que se destaca é o medo, medo de a doença voltar:

Agora, eu tive nesse periodo em 2009, o doutor [...] achou que eu tivesse que fazer talvez outro transplante. Mas aí, ele entrou com outro tratamento e não precisou fazer o transplante e eu tomei quarenta sessões de, é tipo uma quimioterapia. Mas graças a Deus o resultado foi excelente, que nem ele esperava esse resultado. (E3 Hortência)

\section{A vida após o transplante de medula óssea - ressig- nificações no cotidiano}

Apreende-se dos relatos dos sujeitos a existência de um processo de mudança do modo de ver a vida após o TMO. Muitos sujeitos fizeram comparações referentes ao momento anterior e posterior ao TMO, enfatizando a possibilidade de uma nova vida, mudanças e ressignificações de suas vidas após a experiência do transplante:

[...] então esse processo de doença na minha vida mudou muita coisa, entendeu? Mudou os valores, mudou maneira de pensar, mudou tudo, entendeu? Hoje em dia é outra cabeça, outra visão né? (E1 Rosa)

A gente passa a olhar a vida, né, com outro ângulo. A gente fica assim, mais emotiva, coração fica mais mole [...]. (E3 Hortência)

[...] passando por uma outra experiência né, a gente vai mudando, que eu peguei essa doença como um prêmio de Deus, que eu tinha que ter um prêmio, né? fiz tanta coisa boa, será que eu não tinha que ter um prêmio, eu tinha que ter um prêmio, né? Então Ele me deu essa doença, e essa doença me trouxe muita amizade, muito carinho, um mundo muito diferente, um outro conhecimento para vida que eu não tinha [...] então eu tenho ela como um prêmio, e esse transplante foi um troféu, que eu vou levar do hospital. (E4 Lírio)

Não foi nem depois do transplante, mas depois que eu fiquei sabendo da doença. Os valores da gente mudam completamente, coisa que se importava, que achava que era a maior dificuldade, hoje tiro de letra, coisa que para mim agora não tem valor nenhum. Dou muito mais valor à vida, ao dia, porque do mesmo jeito que me aconteceu, não sabe amanhã o que vai acontecer. (E5 Íris)

Eu aprendi a ser mais paciente também, [...] aprendi também que ficar no hospital não é, às vezes, tão fácil igual a gente pensa. (E7 Antúrio)

\section{DISCUSSÃO}

Na primeira categoria desta pesquisa, Afastamento do trabalho, aspectos relacionados à restrição relacionada à prática profissional já vem sendo pautado pela literatura sobre o tema. Reconhece-se que as limitações encontradas na retomada do cotidiano anterior ao TMO 
têm um efeito direto sobre a renda, que, na maioria dos casos, é depreciada devido à restrição ao exercício de atividades determinada pela equipe médica ou pela própria condição física ${ }^{(13)}$.

Complementa-se que ocorre um desafio de readaptação no plano ocupacional que muitas vezes exige drásticas alterações, como a mudança de profissão, sem contar as dificuldades de inserção e reinserção no mercado de trabalho ${ }^{(13)}$.

Os sujeitos Lírio e Violeta explicitaram suas insatisfações sobre a incapacidade de controlar as condições relacionadas à saúde que os impediam de trabalhar. A convivência com a condição limitante, por período prolongado, gerou-lhes um sentimento de impotência. O surgimento de tal sentimento se evidenciou quando refletiam sobre o trabalho como um componente do contexto global de suas vidas e a impossibilidade de executá-lo. O sentimento de impotência encontra-se dentre os diagnósticos de enfermagem da Taxonomia da North American Nursing Diagnoses Association e é definido como

o estado em que o indivíduo percebe uma falta de controle pessoal sobre determinados eventos ou situações, o que afeta o planejamento, as metas e o modo de vida ${ }^{(14: 592)}$.

A evidência dessa demanda aponta para a necessidade de planejamento após a alta, com orientações específicas pelo enfermeiro. Este pode fazer orientações e encaminhamentos mais pontuais ao enfermeiro de família ou de atenção domiciliar, bem como a outros profissionais da equipe de saúde, como o assistente social ou psicólogo.

Também se evidenciou que pessoas que tiveram uma doença grave trazem consigo uma experiência marcada por vivências e angústias relacionadas às manifestações da doença, ao tratamento agressivo e às implicações deste sobre os aspectos da vida pessoal(15). Estas questões nortearam a construção da segunda categoria empírica, Estado de vigília: preocupação constante com recidivas após a alta.

Identifica-se, assim, ambivalência de emoções, vivenciadas no momento da alta, coexistindo o sentimento de alegria com o receio em retornar ao cotidiano e de manter seus cuidados em casa. Extraem-se, da literatura especializada, evidências de que os pacientes que estão há menos tempo transplantados expressam mais claramente a preocupação com a possibilidade de recidiva ${ }^{(8)}$. É como se eles estivessem travando uma luta diariamente contra um fantasma, ou seja, vivenciando uma ameaça constante, geradora de sentimentos de pavor ou ansiedade. Essas preocupações muitas vezes são associadas à necessidade emergencial de se manterem sempre alerta e atentos para não negligenciarem as atividades de autocuidado, se automonitorando.

Em meio a esta discussão, reforça-se a trajetória pessoal do sujeito transplantado, geralmente angustiante, pois já sofreu o impacto do diagnóstico de uma doença potencialmente fatal, a qual funciona como um desencadeador de vivências de ansiedade que interfere no cotidiano do paciente e de seus familiares. Nesse sentido, a vida dos pacientes após o TMO sofre implicações decorrentes deste processo e gera impactos que podem variar segundo o tipo de transplante, a doença de base, os condicionamentos propostos e os medicamentos usados ${ }^{(5)}$.

O enfermeiro torna-se fundamental nesse processo de recuperação, uma vez que possui a responsabilidade pela educação e orientação dos pacientes e de seus familiares sobre cuidados gerais para manutenção da saúde e específicos ao autocuidado após o transplante ${ }^{(16)}$. O

atendimento das necessidades específicas dos pacientes submetidos ao TMO se completa pela presença do enfermeiro ao seu lado, que é a mais extensa e estreita entre a de todos os profissionais envolvidos ${ }^{(9: 465)}$.

A categoria $A$ vida após o transplante de medula óssea - ressignificações no cotidiano indica que as mudanças ocorridas no estilo de vida possuem aspectos subjetivos em relação à conquista alcançada após o TMO. Cabe ressaltar que tal conquista favorece a revisão de conceitos e valores que se tinham antes do procedimento $^{(8)}$. Sobre este aspecto, salienta-se que "a vida depois do transplante é percebida como uma nova vida"(17:118). Reforça que esta nova vida é plena de mudanças significativas, o que também foi identificado neste estudo. A partir dos depoimentos identificou-se que a vivência desse processo gera mudanças na maneira de ser e de estar no mundo, sendo essas questões vivenciadas de forma particular e individual.

Acrescenta-se a este fato que os profundos efeitos no estado emocional no paciente e família produzidos pelo TMO referem-se ao seu caráter de alta complexidade. Tais implicações, decorrentes do transplante, atingem tanto o paciente quanto a família, e contam com as intervenções do enfermeiro nessa adaptação para que conquistem um grau desejado de qualidade de vida. A família pode ser considerada aliada na assistência de enfermagem, pois ela pode fornecer a segurança e o apoio psicológico para a readaptação 
do paciente transplantado ao convívio social ao qual estava habituado ${ }^{(18)}$.

Dessa forma, torna-se imprescindível que essas respostas humanas sejam apreendidas, interpretadas e compreendidas para que o plano de cuidados do profissional atenda às especificidades desse grupo.

\section{CONSIDERAÇÕES FINAIS}

Este estudo evidenciou o investimento dos sujeitos no sentido de obterem uma adaptação ocupacional e social com vistas à retomada da vida cotidiana. Observouse que este processo de busca ocorre paulatinamente, e alguns pacientes têm dificuldade para se readaptarem, mesmo após anos de realização do tratamento.

Além disso, o caminho de readaptação é sinuoso e passível de influência de condições que fogem à governabilidade da pessoa, como complicações clínicas que nem sempre podem ser prevenidas e controladas. Foi possível também evidenciar o desafio da readaptação no plano ocupacional, exigindo muitas vezes alterações, como a mudança ou renúncia da profissão.

Torna-se relevante destacar, portanto, que em alguns casos as condições emocionais se sobrepõem às condições clínicas, interferindo nesse processo de adaptação após transplante. Identificou-se que, mesmo em condições clínicas, favoráveis ao retorno a atividades laborais, os sujeitos não se sentem aptos, evidenciando impotência e manifestando mudanças em seus papéis sociais. O enfermeiro, por meio de técnicas de comunicação e de relacionamento terapêutico, pode apoiar o desenvolvimento de estratégias de enfrentamento e de redefinição dos papéis do transplantado, tanto na família como na sociedade.

Pode-se ainda considerar que o processo referente ao percurso do paciente e família desde o diagnóstico da doença até a alta do TMO influencia no cotidiano em decorrência das mudanças no estilo de vida e de uma nova forma de viver e de ver a vida. Alguns fatores relacionados ao tratamento e ao período de internação, como o isolamento protetor necessário, em períodos de supressão do sistema imunológico, e o próprio transplante em si, envolvem o risco de morte e complicações relacionadas ao tratamento como infecção, diarreia, dor, aquisição de doenças transmissíveis logo após a realização do procedimento, entre outros, podendo gerar impactos relevantes de longa duração na vida dos sujeitos.

A ambivalência de emoções que permeia todo o processo de transplante, incluindo a recuperação dos sujeitos, manifesta-se por meio de atitudes repletas de ansiedade, medo e insegurança que necessitam ser compreendidas e minimizadas em prol de uma readaptação processual e de uma progressiva e plena autonomia do sujeito. Torna-se relevante, pois, a identificação das dificuldades clínicas, emocionais e sociais a que as pessoas submetidas estão expostas, assim como a adoção de condutas que minimizem tal situação.

Finalmente, considera-se que o apoio profissional do enfermeiro ao paciente que vivenciou o TMO deve ocorrer em interlocução com os membros da equipe multiprofissional, e o suporte familiar deve ocorrer durante a trajetória árdua que o transplantado cursa, até a recuperação de sua condição de saúde e social. Salienta-se, enfim, a especificidade do cuidado após o TMO, requerendo atualizações constantes por parte do profissional, uma vez que as orientações para estes pacientes seguem protocolos específicos, mas sem negar a individualidade de cada um. É necessário a incorporação de condutas profissionais que giram em torno de diferentes estratégias, envolvendo a criatividade e a emoção entremeadas com saber científico.

\section{REFERÊNCIAS}

1. Instituto Nacional de Câncer (Brasil). Ações de Enfermagem para o controle do Câncer: uma proposta de integração ensino-serviço. $3^{\mathrm{a}}$ ed. Rio de Janeiro: INCA; 2008.

2. Bonassa EMA. Transplante de medula óssea e de células tronco hematopoéticas. In: Bonassa EMA, Santana TRS. Enfermagem em terapêutica oncológica. $3^{\mathrm{a}} \mathrm{ed}$. São Paulo: Atheneu; 2005. p. 241-68.

3. Ministério da Saúde (Brasil). Portaria $n^{\circ} 2.600 / \mathrm{GM}$ de 21 de outubro de 2009. Aprova o regulamento técnico do Sistema Nacional de Transplantes; 2009.

4. Voltarelli JC, Stracieri ABPL. Aspectos imunológicos dos transplantes de células tronco-hematopoéticas. Medicina. 2000;(33):443-62.

5. Santos MC, Moreira FCFS, Rodrigues MR. Estudo sobre qualidade de vida com pacientes pós-TMO: aplicação do questionário WHOQOL-Bref. Mundo Saúde. 2008;32(2):146-56.

6. Ninin E, Milpied N, Moreau P, André-Richet B, Morineau N, Mahé B, et al. Longitudinal study of bacterial, viral and fungal infections in adult recipients of bone marrow transplants. CID. 2001;33(1):41-7. 
7. Soares LC, Burille A, Antonacci MH, Santana MG, Schwartz E. Quimioterapia e seus efeitos adversos: relato de clientes oncológicos. Cogitare enferm. 2009;14(4):714-9.

8. Mastropietro AP, Santos MA, Oliveira EA. Sobreviventes do transplante de medula óssea: construção do cotidiano. Rev. Ter. Ocup. Univ. São Paulo. 2006;17(2):64-71.

9. Anders JC, Soler VM, Brandão EM, Vendramini EC, Bertagnolli CLS, Giovan PG, et al. Aspectos de enfermagem, nutrição, fisioterapia e serviço social no transplante de medula óssea. Medicina. 2000;(33):463-85.

10. Minayo MCS. O desafio do conhecimento: pesquisa qualitativa em saúde. $8^{\text {a }}$ ed. São Paulo: Hucitec; 2004.

11. Brasil. Conselho Nacional de Saúde. Comitê Nacional de Ética em pesquisa em Seres Humanos. Resolução $\mathrm{n}^{\circ}$ 196, de 20 de outubro de 1996. Diretrizes e normas regulamentadoras de pesquisas envolvendo seres humanos. Brasília; 1996.

12. Mazzotti AJA. Usos e abusos dos estudos de caso. Cad. Pesqui. 2006;36(129):637-51.

13. Mastropietro AP, Oliveira-Cardoso EA, Simões BP, Voltarelli JC, Santos MA. Relação entre renda, trabalho e qualidade de vida de pacientes submetidos ao transplante de medula óssea. Rev. Bras. Hematol. Hemoter. 2010;32(2):102-7.

14. Carpenito-Moyet LJ. Diagnósticos de enfermagem: aplicação à prática clínica. $11^{\mathrm{a}} \mathrm{ed}$. Artmed. Porto Alegre; 2009.

15. Campos EMP, Bach C, Alvares M. Estados emocionais do paciente candidato a transplante de medula óssea. Psicol. teor. prat. 2003;5(2):23-36.

16. Lacerda MR, Lima JBG, Barbosa R. Prática de enfermagem em transplante de células tronco hematopoéticas. Rev. Eletr. Enf. [Internet] 2007;9(1):24250 .

17. Soares TC. O transplante e a questão da alteridade: biologia e subjetividade. [tese]. Rio de Janeiro (RJ): Escola Nacional de Saúde Pública Sergio Arouca; 2009.

18. Matsubara TC, Carvalho EC, Canini SRMS, Sawada NO. Family crisis in the context of bone marrow transplantation: an integrative review. Rev. Latino-Am. Enfermagem. 2007;15(4):665-70. 